\title{
Breves comentários sobre metáfora (Übertragung) e linguagem no jovem Nietzsche
}

\section{Brief comments on metaphor (Übertragung) and language in young Nietzsche}

\section{Laura Elizia Haubert}

Graduação em Filosofia (2017). Pontifícia Universidade Católica de São Paulo, Faculdade de Filosofia, Comunicação, Letras e Artes.

RESUMO: Este trabalho apresenta o conceito de metáfora na filosofia da linguagem do jovem Nietzsche na obra Verdade e mentira no sentido Extra-Moral, a partir das influências recebidas por Nietzsche de suas leituras durante o começo da década de 1870, apontando os principais filósofos, bem como cientistas naturais que influenciaram o entendimento do autor da metáfora como Übertragung, uma ação transformadora e criativa que desempenha papel ativo na construção da linguagem como meio de relação do homem com o mundo a partir de um caráter artístico.

Palavras-chave: linguagem; metáfora; arte; realidade; coisa em si.

ABSTRACT: This work presents the concept of metaphor in the philosophy of the language of the young Nietzsche in the work On truth and lying in an Extra-Moral sense, from the influences received by Nietzsche from his readings during the beginning of the 1870s, pointing the main philosophers as well as natural scientists which influenced the author's understanding of metaphor as Übertragung, a transformative and creative action that plays an active role in the construction of language as a means of relating man to the world from an artistic character.

Keywords: language; metaphor; art; reality; thing-in-itself. 


\section{Introdução}

Discutiremos a concepção de linguagem no pensamento do jovem Nietzsche, notadamente no ano de 1873 quando no ensaio Verdade e mentira no sentido Extra-Moral ${ }^{1}$ o conceito de metáfora é apresentado aos leitores, surgindo como uma segunda hipótese de interpretação do autor para o tema da linguagem e sua origem. ${ }^{2}$

A linguagem foi um dos temas que mais interessou os filósofos durante o século XVIII, e floresceu com mais força no século XIX, com destaque para a Alemanha e suas novas pesquisas nas áreas de filosofia da linguagem e linguística. De acordo com Cloeren (1988), os filósofos alemães estavam interessados em dois problemas: primeiramente, a influência da linguagem na filosofia; em segundo lugar, a relação possível entre linguagem e pensamento.

\footnotetext{
${ }^{1} \mathrm{O}$ singular ensaio "Verdade e Mentira no Sentindo Extra-Moral" veio à luz durante junho de 1873 segundo apontam as pesquisas de Janz (2016) quando Nietzsche debilitado por problemas de saúde recorrentes solicita ao seu amigo Gersdorff que escreve mediante os ditados de Nietzsche. Segundo Lopes (2006), no planejamento inicial o ensaio faria parte de uma obra maior intitulada "O Livro do Filósofo" que contaria com cinco seções, mas que jamais chegou a ser finalizado. Apesar de seu status de texto inacabado a obra possui grande importância por dois motivos, de acordo com Janz (2016): (i) o texto é sua primeira excursão ousada por problemas epistemológicos; (ii) o ensaio rompe com os trabalhos até então publicados por Nietzsche. Para Clark (1990, p.64) “[...] ao contrário das notas da década de 1880, VM não pode ser dispensado com o argumento de que pertence apenas ao Nachlass, pois possui, em um grau relativamente alto, as características que tornam os trabalhos publicados mais confiáveis do que o Nachlass para a interpretação das posições de Nietzsche. Um ensaio retrabalhado e polido, não é uma mera nota que Nietzsche poderia ter pensado melhor no dia seguinte. Embora ele não tenha publicado, ele faz alusão a ele com aprovação em um trabalho publicado, e seu comprimento somasse como uma ponte óbvia entre os trabalhos anteriores e posteriores que ele publicou [...]." Tradução livre de: "Further, unlike the notes of the 1880s, TL cannot be dismissed on the grounds that it belongs only to the Nachlass, for it possesses, to a relatively high degree, the characteristics that make the published works more reliable than the Nachlass for the interpretation of Nietzsche's position. A reworked and polished essay, it is not a mere note that Nietzsche may have thought better of the next day. Although he did not publish it, he does allude to it with approval in a published work, and its length plus its status as an obvious bridge between earlier and later works he did publish [...]". (CLARK, 1990, p.64).
}

2 Segundo o entendimento de Haar (1996, p.70-71) “Nietzsche formulou quase simultaneamente duas hipóteses, derivando a linguagem por um lado da música e por outro lado da metáfora. Só mais tarde ele descobrirá a unidade e a convergência dessas aparentes fontes separadas, mas sem nunca negar ou modificar sua posição inicial. A visão única e constante de Nietzsche permanece que a linguagem se deriva de um elemento pré-linguístico que o controla e é essencialmente 'estético'. A aparente divergência entre música e metáfora resolve-se dentro do núcleo da Vontade de Poder artística, a origem de toda ficção." Esse duplo desenvolvimento pode ser melhor observado contrapondo seus primeiros textos com o ensaio Verdade e Mentira em um Sentido Extra-Moral, pois “em contraste com o texto anterior, 'Verdade e Mentira' não contém referências à música e à possibilidade de uma compreensão intuitiva e pré-linguística do ser. A ausência de qualquer discussão sobre a música, bastante marcante, torna-se mais marcante quando consideramos a crítica do conceito ensaiado por Nietzsche neste texto." (KLEIN, 1997, p.97). Assim, observa-se que neste ensaio não é mais a música que é utilizada como ferramenta para abordar a linguagem, mas sim a metáfora que serve como ponto de partida de uma percepção corporal, como explicou Haar (1996) ao pontuar que toda metáfora é uma experiência de transposição. Em resumo, acompanhou-se o entendimento de Brown (2006, p.93) na afirmação de que "os primeiros escritos de Nietzsche adotam uma hierarquia de metáfora com música no topo, a linguagem falada abaixo e a linguagem escrita ainda mais abaixo." O presente artigo se concentrará em apresentar justamente o ensaio de Nietzsche que se preocupa com a metáfora. Contudo, vale ainda destacar que a metáfora é apenas uma das demais figuras de linguagem que Nietzsche está interessado, neste ensaio ele foca-se na metáfora, mas em um texto anterior intitulado "Escritos sobre Retórica" Nietzsche desenvolve segundo De Man (1974) uma teoria dos tropos que abrange a metáfora, metonímia e sinédoque, além de contemplar também figuras como alegoria ou ironia, a lista de Nietzsche contém ao menos trinta modos distintos.

Tradução livre de: “Nietzsche formulated nearly simultaneously two hypotheses, deriving language on the one hand from music and on the other from metaphor. Only later will he discover the unity and convergence of these apparently separate sources, but without ever denying or modifying his initial position. Nietzsche's unique and constant insight remains that language derives from a pre-linguistic element that controls it and is essentially 'aesthetic'. The apparent divergence between music and metaphor resolves itself within the core of the artistic Will to Power, the origin of every fiction." (HAAR, 1996, p.70-71).

Tradução livre de "In contrast with the earlier text, 'On Truth and Lie' contains no references to music and to the possibility of an intuitive, pre-linguistic understanding of being. The absence of any discussion of music, itself quite striking, becomes most marked when we consider the critique of the concept essayed by Nietzsche in this text. [...]" (KLEIN, 1997, p.97)

Tradução livre de "Nietzsche's early writings adopt a hierarchy of metaphor with music at the top, spoken language below, and written language lower still." (Brown, 2006, p.93). 
Na concepção de Glock (2015), os autores preocupados com a linguagem durante o século XIX alemão podiam ser divididos em três grupos de pesquisa, os hermenêuticos, os lógicos, e, por último, os ligados à crítica da linguagem. Nietzsche encontra-se no terceiro grupo, sendo um dos representantes mais interessantes deste. ${ }^{3}$

O filósofo alemão é um desses principais críticos porque utiliza a linguagem, segundo Fink (1983), como um ponto de partida para realizar análises e críticas das convenções sociais, o problema do conhecimento, da verdade e também da ciência, além da própria filosofia. A linguagem é a ferramenta por meio da qual ele realiza sua crítica.

A obra de 1873, Verdade e mentira no sentindo Extra-Moral, interessa aos leitores por sua crítica da verdade e do conhecimento. Contudo, a obra se destaca principalmente pela definição de linguagem, que Nietzsche se dedica a exemplificar nas páginas do breve texto dividido em duas partes, abrangendo dez parágrafos na primeira e quatro na segunda.

Nessa obra, o interesse de Nietzsche (2008) se volta para o conceito de metáfora, a linguagem é compreendida como metáfora, mas o que não recebeu tanta atenção dos comentadores foram as influências que o filósofo alemão revela ao realizar a conexão entre metáfora e linguagem. Para Brobjer (2008), ele está claramente influenciado por Schopenhauer, Gerber e Lichtenberg. ${ }^{4}$

A influência de Schopenhauer opera nesta obra de 1873 no que diz respeito à relação entre linguagem e verdade, pois, tendo em vista o que escreveu Moreira (2013, p.277), o tema no jovem filósofo "[...] parece ter sua origem nos estudos de filologia conduzidos pelo jovem Nietzsche. Mas, acreditamos que também podemos encontrá-lo nos debates com a filosofia schopenhaueriana."

Não obstante, apesar influência de Schopenhauer, a figura de destaque dentre esses três é Gustav Gerber. Gerber compõe, junto com Vico, Wolfgang von Goethe, Richter, Biese e outros, segundo Nerlich e Clarke (2001), o conjunto de filósofos interessados nos estudos da linguagem a partir da retórica e da metáfora.

A obra mais conhecida de Gerber é a Die Sprache Als Kunst (A linguagem como arte), que influenciou profundamente Nietzsche quando a leu em 1873. De acordo com Santiago Guervos (2000, p.17):

O livro trata de diferentes temas de filosofia da linguagem e está a meio caminho entre a ciência da linguagem e a filosofia. [...] A tese indicada no título da obra - A linguagem como arte - baseia-se em uma série de autores como Herder, Humboldt, Grimm, Jean Paul, Hegel, etc., sem esquecer os antecedentes do romantismo alemão, acima de tudo, F. Schlegel. Para ele, ao descrever a linguagem "viva" não se pode recorrer à sintaxe e ao léxico, que são abstrações justificáveis para a ciência da linguagem, senão à linguagem "como uma forma de arte". O que é fundamental é o impulso artístico (Kunsttrieb) cujo produto é essa arte inconsciente ou criação inconsciente. No fundo, o que Gerber já começa a questionar é que a linguagem é essencialmente um meio de comunicação; seu

\footnotetext{
${ }^{3}$ No entendimento de Forster (2011, p.267) do grupo no qual Nietzsche se encontra "Nietzsche é o membro mais original desse grupo." Tradução livre de "Nietzsche is the most original member of this group."

${ }^{4} \mathrm{O}$ autor não descarta a existência de outras influências, porém aponta para o caráter majoritário destes três autores frente aos demais. Brobjer (2008, p.56) assegura: "No entanto, as possíveis influências antigas não parecem ter sido cuidadosamente examinadas - por exemplo, Demócrito, Epicuro, Platão e Aristóteles -, bem como estudos de visões antigas e usos da linguagem sobre a qual ele leu (e pensou) bastante extensivamente, como F. Blass e T. Benfrey." Tradução livre de "However, possible ancient influences do not seem to have been thoroughly examined - for example, Democritus, Epicurus, Plato, and Aristotel - as well studies of ancient views and uses of language about which he read (and thought) fairly extensively, such as F. Blass and T. Benfrey."
} 
caráter original, agora esquecido pelo homem, é ser uma “obra de arte". (SANTIAGO GUERVÓS, 2000, p.17). ${ }^{5}$

A tese de que parte Gerber, conforme comenta Santiago Guervós (2000), é de que a linguagem passa a ser observada como um meio de abstrações artísticas, e não mais apenas como uma ferramenta que conecta homem e mundo atuando na forma de comunicação. Em Gerber, o problema é: em que medida a linguagem é uma obra de arte, ou seja, uma construção do homem?

Em boa medida, argumento semelhante será encontrado na obra de 1873, exceto que Nietzsche passou também pelo crivo das leituras de Lichtenberg e de fisiólogos e cientistas naturais contemporâneos, conforme destacou Mattioli (2010). Por isso seu vocabulário, ao tratar da metáfora, é também um linguajar científico-natural, e não apenas artístico-retórico, como se verá a seguir.

Lichtenberg marca Nietzsche primeiramente por seu caráter de escrita aforístico, que será melhor desenvolvido na fase seguinte com o livro Humano, demasiado humano, mas, no entender de Westerdale (2013), Nietzsche é influenciado principalmente pela noção de corpo de Lichtenberg. Para ele o corpo desempenha um papel nas atividades intelectuais, inclusive na formação da linguagem.

Observa-se que estes três autores fornecem as bases das premissas apontadas por Nietzsche na obra de 1873, Verdade e mentira, mas não são únicos; ao elemento filosófico se unem também conhecimentos fisiológicos e científicos que interessavam ao jovem Nietzsche, como se expõe abaixo.

\section{Metáfora e linguagem em Nietzsche}

O problema da metáfora aparece no texto do jovem filósofo durante suas pesquisas de compreensão das unidades da linguagem. Nietzsche (2008, p.30) intenta desmontar a língua para descobrir se em sua estrutura ela é capaz ou não de, em última instância, fornecer a verdade transcendental ${ }^{6}$ que organiza e representa o mundo tal como a filosofia clássica buscou. Por isso, ao voltar-se para a investigação da linguagem, ele parte da pergunta "O que é uma palavra?".

Nietzsche (2008, p.30) responde à sua questão logo em seguida, afirmando que a palavra nada mais é que "a reprodução de um estímulo nervoso em sons. Mas deduzir do estímulo nervoso uma causa fora de nós já é o resultado de uma aplicação falsa e injustificada do princípio de razão".

A primeira resposta de Nietzsche à indagação pelo que é palavra constitui-se, de acordo com Bornedal (2010, p.55), de dois momentos distintos. O primeiro é marcado por uma resposta precipitada, pois "se a palavra representasse um estímulo nervoso,

\footnotetext{
${ }^{5}$ Tradução livre de “El libro trata distintos temas de filosofía del lenguaje y se encuentra a medio camino entre la ciencia del linguaje y la filosofía. [...] La tesis enunciada en el título de su obra - El lenguaje como arte - se basa en una serie de autores como Herder, Humboldt, Grimm, Jean Paul, Hegel, etc., sin olvidar los antecedentes del romanticismo alemán, sobre todo, F. Schlegel. Para él, a la hora de describir el lenguaje «vivo» no se puede acudir a la sintaxis y al léxico, que son abstracciones justificables para la ciencia del lenguaje, sino al lenguaje "como forma de arte». Lo fundamental es el impulso artístico (Kunsttrieb) cuyo producto es ese arte inconsciente o creación inconsciente. En el fondo lo que Gerber comienza ya a cuestionar es que el lenguaje sea esencialmente un medio de comunicación; su carácter original, ahora olvidado por el hombre, es ser una «obra de arte»." (SANTIAGO GUERVÓS, 2000, p.17)

${ }^{6}$ Segundo destacou Abel (2002, p.15-16) "“Verdade” é a palavra-chave da filosofia ocidental, que no âmago foi a metafísica. Atingir a verdade é uma meta pela qual são prometidas elevadas recompensas intelectuais, morais, religiosas e metafísicas. [...] A crítica dessas concepções e, portanto, do âmago da metafísica ocidental, radicaliza-se, sobretudo, com Nietzsche. No pensamento de Nietzsche, não se trata simplesmente de substituir as representações anteriores de verdade por uma outra. Ao contrário, é a arquitetura do questionamento mesma, ou seja, do sentido da verdade, que é reinterpretada." Nesta obra de 1873 Nietzsche ataca a verdade utilizando-se de uma crítica da linguagem como vê-se acima.
} 
a reivindicação seria que temos acesso direto a processos fisiológicos inconscientes." ${ }^{77}$ Mas, se este fosse realmente o caso, Nietzsche estaria apenas transformando a linguagem em um instrumento que converte as sensações corpóreas em palavras. Na segunda parte de seu argumento, Nietzsche parece repensar a própria afirmação anterior e a reformular, de modo que se possa compreender que o estímulo não se encontra completamente fora do corpo em forma: a linguagem não é, portanto, meramente um conversor.

A definição de Nietzsche das palavras, de que estas tornam os estímulos em sons, surge, segundo Denat (2012), de uma incapacidade da linguagem para constituir o mundo de forma perfeita para o homem, pois sua reprodução é imperfeita na esfera sensitiva e visual, tendo em vista que ambas se encontram em esferas de ordens completamente diferentes. Contudo, o que isso significa?

A linguagem não pode representar o mundo com perfeição porque ela não está no mundo da realidade empírica. O que sucede é que o homem não se dá conta deste fenômeno, pois, como esclarece Emden (2005), a humanidade deposita na linguagem a crença de que ela é capaz de representar o mundo, de que se pode fundir palavra e coisa, muito embora isto seja apenas uma ilusão gerada pelo próprio poder da linguagem.

Na relação entre a linguagem e o mundo enquanto verdade, Nietzsche (2008, p.30-31) escreve:

Como poderíamos, caso tão-somente a verdade fosse decisiva na gênese da linguagem, caso apenas o ponto de vista da certeza fosse algo decisório nas designações, como poderíamos nós, não obstante, dizer: a pedra é dura; como se esse "dura" ainda não fosse conhecido de alguma outra maneira e não só como um estímulo totalmente subjetivo! Seccionamos as coisas de acordo com gêneros, designamos a árvore como feminina e o vegetal como masculino: mas que transposição arbitrárias! Quão longe voamos para além do cânone da certeza! Falamos sobre uma serpente: a designação não tange senão ao ato de serpentear e, portanto, poderia servir também ao verme. Mas que demarcações arbitrárias, que preferências unilaterais, ora por esta, ora por aquela propriedade de uma dada coisa! (NIETZSCHE, 2008, p.30-31).

Esse parágrafo é, segundo Forster (2011), um dos três principais da argumentação de Nietzsche. A pedra de toque reside em que a aplicação de qualquer palavra, ou mesmo conceito, a uma experiência do mundo empírico distorce as abstrações realizadas por vias subjetivas da perspectiva humana. Isso ocorre porque a linguagem, ao tentar traduzir o mundo, distorce-o em uma perspectiva antropomórfica que não representa o mundo em si, mas apenas o modo como é apreendido pela linguagem.

Esse antropomorfismo que Nietzsche aponta na linguagem como distorção do mundo aparece, segundo Sá Moreira (2013, p.283-284), nos três exemplos dados quando o autor se refere à pedra, ao vegetal e à serpente. No caso da primeira, se diz que a pedra é "dura" sem analisar-se previamente que a dureza não pode ser uma realidade em si: ela nada mais é que uma interpretação humana da experiência transformada em palavra. No caso do vegetal, a palavra alemã Baum (árvore) é masculina, enquanto Pflanze (planta/vegetal) é feminina, não obstante uma árvore é um vegetal - os gêneros não pertencem ao mundo, mas, novamente, são criações antropomórficas da linguagem. O mesmo sucede com a serpente, Schlange em alemão, que poderia também servir para dizer verme, Wurme, já que se trata de sichwinden (enrodilhar-se), mas não é isso que sobrevém.

Na compreensão de Gray (2012), o intento de Nietzsche com esses exemplos é mostrar que a arbitrariedade das palavras, por exemplo, nos gêneros ou características que impõe, é responsável não por traduzir o mundo ao homem, mas, pelo contrário, por alterar a realidade ao tentar expressá-la.

7 Tradução livre de "if the word represented a nerve-stimulus, the claim would be that we have direct access to unconscious physiological processes." 
O segundo argumento de Nietzsche para provar essa visão de que a linguagem altera a realidade diz respeito aos diferentes idiomas existentes. Observa-se o seguinte trecho:

Dispostas lado a lado, as diferentes línguas mostram que, nas palavras, o que conta nunca é a verdade, jamais uma expressão adequada: pois, do contrário, não haveria tantas línguas. A "coisa em si" (ela seria precisamente a pura verdade sem quaisquer consequências) também é, para o criador da linguagem, algo totalmente inapreensível e pelo qual nem de longe vale a pena esforçar-se. (NIETZSCHE, 2008, p.31).

Partindo da premissa de que a linguagem teria uma relação de pertinência com a verdade, não seria possível assegurar a razão da existência de tantas diferentes línguas, já que apenas uma seria a expressão verdadeira que abarcaria sozinha toda a "coisa em si" do mundo, ou seja, a pura verdade, sendo as demais línguas constituídas de meros erros.

Tendo em vista que como na linguagem o que desempenha o papel principal não é a verdade e que a linguagem se constitui de palavras que não expressam com completa adequação o mundo, Nietzsche pergunta-se pelo o que é a linguagem. Justamente é essa indagação que lança luz sobre o terceiro e mais importante componente de sua argumentação na obra de 1873: a metáfora.

O filósofo alemão escreve a respeito desta indagação:

A coisa em si (ela seria precisamente a pura verdade sem quaisquer consequências) também é, para o criador da linguagem, algo totalmente inapreensível e pelo qual nem de longe vale a pena esforçar-se. Ele designa apenas as relações das coisas com os homens e, para expressá-las, serve-se da ajuda das mais ousadas metáforas. De antemão, um estímulo nervoso transposto em uma imagem! Primeira metáfora. A imagem, por seu turno, remodelada num som! Segunda metáfora. E, a cada vez, um completo sobressalto de esferas em direção a uma outra totalmente diferente e nova. (NIETZSCHE, 2008, p.31).

A linguagem é responsável por mediar a relação entre os homens e as coisas; mais propriamente, ela reúne em seus saltos a comunhão de diferentes esferas, já que a coisa em si jamais é acessível e nem vale o esforço. Conforme escreveu Nietzsche (2008), a linguagem se compõe de uma trindade de metáforas que se reúnem no esquema de: estímulo/imagem - som - palavra.

Segundo o comentário de Lacoue-Labarthe (1993, p.24), o que sucede é que entre a linguagem e a coisa em $\mathrm{si}^{8}$ do mundo há três diferentes esferas (estímulo/imagem-som-palavra) que impedem a passagem direta e tornam os resultados da assimilação heterogêneos, de modo que "A linguagem é fundada em um intervalo originário e irredutível [écart] por meio do qual ele força o seu caminho, identificando o não-idêntico, introduzindo analogia." ${ }^{\prime \prime}$

Na busca por melhor compreensão do significado do termo metáfora a que Nietzsche se refere, distribuem-se três momentos de entendimento: (I) o que é o termo metáfora? (II) as influências da ciência natural na descrição nietzschiana do termo metáfora; $\mathrm{e}$ (III) o que significa dizer que a linguagem é metafórica.

O primeiro tópico aborda o modo pelo qual Nietzsche compreende o termo metáfora nessa obra. Para Johnson (1981), o que Nietzsche pretende ao utilizar o termo metáfora é dar conta não somente de uma entidade linguística, mas antes imbuir nela um processo ativo, que vai de encontro com o mundo, uma mediação que é capaz de abarcar as diferentes esferas, as quais sozinhas não se inter-relacionam.

\footnotetext{
${ }^{8}$ Neste texto de 1873 Nietzsche ainda trabalha com o conceito de coisa em si kantiano, não obstante o mesmo cai em descrédito nos textos seguintes.

${ }^{9}$ Tradução livre de "Language is founded on an originary and irreducible gap [écart] across which it forces its way by identifying the non-identical, by introducing analogy."
} 
Posição semelhante é expressa por Denat (2012), ao afirmar que a metáfora não é a imagem ou o som propriamente, mas antes o próprio movimento de transposição das esferas, ou seja, o ato de saltar de uma para a outra e, por consequência, produzir ao final deste processo as palavras que compõem o arcabouço da linguagem, que é responsável por descrever o mundo.

Esta noção de metáfora ${ }^{10}$ não como mera figura retórica de troca, porém antes como uma ação de transferência, se conecta com as influências que Nietzsche recebeu, segundo Emden (2005), ao menos de três fontes diferentes: primeiro os gregos e o termo original metáfora (meta + pherein), que no latim equivale a tradução, em segundo de Schopenhauer, que define eloquência como transferência e, por último, Lichtenberg, que assumiu a realidade externa do mundo como embasada nesse processo de transferência.

Vale atentar para o fato histórico de que o termo metáfora (Übertragung) utilizado por Nietzsche foi uma das palavras-chave das ciências naturais da segunda metade do século XIX, conforme escreveu Emden:

Übertragung e a transferência são os termos da fisiologia e da psicologia do século XIX usados
para denotar a relação entre o estímulo nervoso inicial e os estados mentais subsequentes.
Quando Helmholtz mediu a taxa de condução nervosa e descobriu que a transmissão do
impulso nervoso dos estímulos à sensação é relativamente lenta, ele introduziu um modelo
indutivo embasado na relação entre estímulo particular e processos mentais mais gerais. Não só
isso é uma posição empirista na medida em que retrata a aquisição da crença para se basear
na experiência sensorial; além disso, isso implica que o pensamento resulta de transmissões
eletro-motivas. (EMDEN, 2005, p.96). ${ }^{11}$

De fato, o termo transferência foi comum às ciências do século XIX, sobretudo em território de fala germânica, servindo especialmente à fisiologia e a psicologia, e autores como Helmholtz, Wundt ${ }^{12}$ e Otto Caspari são alguns dos principais representantes de sua utilização nas ciências naturais, na busca em observar a condução nervosa de um estímulo em um músculo do indivíduo até o momento de sua recepção cerebral.

Ainda que não se possa dizer com precisão que a linguagem em Nietzsche nasce a partir unicamente dos reflexos corpóreos, este corpo, sem dúvidas, desempenha um papel em sua filosofia. Como pontuou Kremer Marietti (2008), quando Nietzsche utiliza o mesmo termo, ele se refere à estrutura do pensamento, no entanto, a partir da experiência sensitiva há constantemente o jogo de uma função corporal estar envolvida na atividade do pensar.

Uma das relações que se pode demonstrar é a da própria terminologia, a descrição de Nietzsche (2008, p.31) de que as palavras são metáforas que transpõem "a cada vez, um completo sobressalto de esferas [...]", como o filósofo escreve no ensaio, demonstra que:

Brevemente, podemos dizer que a apropriação que o jovem Nietzsche faz da noção de metáfora, por exemplo, como modelo descritivo dos processos cognitivos de construção de uma imagem de mundo, corresponde a uma tentativa de trazer para o interior da reflexão

\footnotetext{
${ }^{10} \mathrm{O}$ termo utilizado por Nietzsche em alemão é Übertragung que aparece repetidamente segundo Emden (2005) em suas notas e escritos do período de 1872-1873, sendo que pode ser entendido como metáfora ou como transferência.

${ }^{11}$ Tradução livre de Übertragung and transference are the terms nineteenth-century physiology and psychology used to denote the relation between initial nerve stimulation and subsequent mental states. When Helmholtz measured the rate of nerve conduction and found that the transmission of the nervous impulse from stimuli to sensation is relatively slow, he introduced an inductive model based on the relation between particular stimulation and more general mental processes. Not only is this an empiricist position in that it portrays the acquisition of belief to be based on sensory experience; in addition, it implies that thinking results from electromotive transmissions. (EMDEN, 2005, p.96).

${ }^{12}$ À luz da pesquisa de Brobjer (2008, p. 232) observa-se que Nietzsche na primavera de 1868 anotou dois títulos da obra de Helmholtz como futuras leituras, são elas: “Helmholtz, Über die Erhaltung der Kraft (Berlin, 1847) Helmholtz, Über die Wechselwirkung der Naturkräfte (1854)" além da obra de Wundt "Vorlesungen über die Menschen- und Thierseele".
} 
filosófica elementos teóricos retirados tanto da fisiologia quanto das ciências da natureza, particularmente da fisiologia. (MATTIOLI, 2010, p.40).

Esse empréstimo realizado por Nietzsche pode ser contemplado ainda no ensaio Verdade e Mentira no sentido Extra-Moral, no momento em que o filósofo se utiliza de um experimento científico emprestado da física, para compor seu argumento. Isso é observável na passagem abaixo:

Pode-se conceber um homem que seja completamente surdo e que jamais tenha tido uma sensação do som e da música: da mesma forma que este, um tanto espantado com as figuras sonoras de Chladni sobre a areia, encontra suas causas na vibração das cordas e jurará que agora não pode mais ignorar aquilo que os homens chamam de som; assim também sucede a todos nós com a linguagem. (NIETZSCHE, 2008, p.31-32).

Nietzsche (2008) se utiliza do exemplo das figuras de Ernst Chladni ${ }^{13}$ para demonstrar que, com as palavras, acontece algo semelhante com o sucedido neste experimento, porém, nesse caso as imagens geradas correspondem ao que o ouvido humano capta como som. Dito de outra forma, a experiência demonstra como é possível passar de diferentes esferas, do som à imagem e, por fim, à palavra.

Autilização da experiência de Chladni demonstra que Nietzsche (2008) se encontrava, de fato, frente a algum panorama científico de seu período, ainda que seus conhecimentos a respeito das pesquisas fossem limitados..$^{14}$ Seus maiores interesses se concentravam nas áreas da fisiologia, psicologia e medicina. ${ }^{15}$

\footnotetext{
${ }^{13}$ Em explicação ao experimento de Chladni, Llinares (2015, p.67-68) analisa: “A comparação é magnífica e encerra o que poderíamos denominar a "Bildtheorie" [teoria da imagem] de Nietzsche. As figuras de Chladni, uma das mais solicitadas demonstrações nas instituições de acústica de nossos modernos museus de ciências, são as diversas configurações que adotam os montes de pó ou de área sobre a superfície de uma placa metálica, quando esta vibra ao tocar ou pulsar determinados instrumentos musicais, um tambor ou um piano, por exemplo. A areia se acumula então nas zonas de amplitude mínima das vibrações, e o número dos montes curvados que se formam varia segundo a frequência de tais vibrações, maior ou menor segundo a agudeza ou a gravidade dos sons produzidos. Pois bem, essas figuras plásticas demonstram oticamente propriedades físicas do som, a saber, as ondas sonoras e sua longitude. A musicalidade final, portanto, não é nenhum traço notável para a transmissão do sentimento, mas uma característica heterogênea que sublinha a mudança de níveis no processo de comunicação, isto é, a radical inadequação da linguagem verbal."
}

${ }^{14} \mathrm{O}$ interesse pela ciência de Nietzsche é notável, a exemplo: "O interesse de Nietzsche nas ciências da vida é fundamental para o desenvolvimento de seu projeto filosófico como um todo. Em uma carta enviada no verão de 1881 de Sils Maria para seu amigo íntimo Franz Overbeck em Zurique, ele observou enfaticamente: 'Digo com conviç̧ão: o pouco que posso trabalhar com meus olhos pertence quase exclusivamente a estudos fisiológicos e médicos (Estou tão mal informado! - e realmente tenho de saber muito!)". Tradução livre de: "Nietzsche's interest in the life sciences is central to the development of his philosophical project as a whole. In a letter he sent in the summer of 1881 from Sils Maria to his close friend Franz Overbeck in Zurich, he noted emphatically: "Said in confidence: the little I can work on with my eyes belongs almost exclusively to physiological and medical studies (I am so badly informed! - and really have to know so much!)" (EMDEN, 2014, p.9)"

${ }^{15}$ Segundo Emden (2005, p.100), “Embora Nietzsche estivesse certamente ciente desses desenvolvimentos por meio do seu interesse contínuo pelas ciências naturais, seu conhecimento da física do século dezenove era sem dúvida relativamente limitado. A pesquisa sobre as correntes elétricas não se restringiu à ciência exata da física, no entanto, para as ideias de Galvani e Ritter sobre 'eletricidade animal', ou mais precisamente, 'eletricidade orgânica', recebeu muita atenção nos círculos médicos, e os geradores eletrostáticos foram ocasionalmente usados em tentativas de curar doenças e distúrbios nervosos e dores de cabeça a surdez e cegueira. A gama desses experimentos se aproxima do estranho, mas mesmo assim, a conexão entre a eletricidade e a fisiologia dos organismos vivos se tornou um paradigma bastante estabelecido. De fato, recebeu atenção renovada ao longo do século XIX, de modo que, em seu volumoso Untersuchungen über thierische Electrictität (1848-84), por exemplo, atentou Emil DuBois-Reymond." Tradução livre de "Although Nietzsche was certainly aware of these developments through his ongoing interest in the natural sciences, his knowledge of nineteenth-century physics was no doubt relatively limited. Research into electric currents was not restricted to the exact science of physics, however, for Galvani's and Ritter's ideas about "animal electricity," or more precisely, "organic electricity," received much attention in medical circles, and electrostatic generators were occasionally used in attempts to cure ailments from nervous disorders and headaches to deafness and blindness. The range of these experiments often verges on the bizarre, but even so, the connection between electricity and the physiology of living organisms became a fairly well established paradigm. Indeed, it received renewed attention throughout the nineteenth century, so that in his voluminous Untersuchungen über thierische Electricität (1848-84), for instance, Emil DuBois-Reymond attempt." 
À luz da pesquisa de Pia Daniela Volz apud Emden (2005, p.101), demonstrou-se que Nietzsche estava ciente dessas pesquisas, que relacionavam os impulsos nervosos sensitivos e o cérebro, já que o filósofo foi um leitor de estudos como os de Eduard Hitzig, que se dedicou a "discutir a identificação de regiões sensoriais e motoras no córtex cerebral, bem como experiências que mostram que o estímulo elétrico deste último leva a movimentos de músculos relacionados." ${ }^{16}$ Nietzsche, ainda segundo Pia Daniela Volz, leu autores como Lange The History of Materialism e Alexander Bain Mind and Body, que contribuíram aos temas da relação entre nervo e cérebro, bem como linguagem.

Também se destacaram em suas influências as leituras de Otto Funke, vide o excerto de Emden:

Esta descrição de tradução da percepção sensorial é explicada com mais detalhes na Lehrbuch der Physiologie de Otto Funke (1855-57), que Nietzsche leu em 1870 pouco depois de voltar sua atenção para o problema da linguagem e enquanto ele já estava trabalhando em suas palestras posteriores de retórica. Presumivelmente, o volumoso trabalho de Funke influenciou o conhecimento científico de Nietzsche, bem como seu conceito de Übertragung. De fato, Funke é bastante explícito e descreve a fibra nervosa como um 'condutor', isto é, um 'mecanismo' que transfere um impulso particular de uma extremidade para outra, conectando-se a outras fibras nervosas. A este respeito, Funke conclui, o processo envolvido na percepção humana deve ser entendido literalmente como uma 'transmissão de fibra para fibra'. (EMDEN, 2005, p.104-105) ${ }^{17}$.

Observou-se que Otto Funke descreveu os nervos do corpo como fios condutores, que organizavam contínuas transferências, as quais saltavam por diferentes esferas do corpo. Segundo Emden (2005), Nietzsche leu a obra de Funke no ano de 1870, logo que se voltou ao problema da linguagem como metáfora e, embora não se possa declarar que ele é a principal fonte desta noção, sem dúvida influenciou o pensamento nietzschiano, basta que se atente para as semelhanças nas ideias de saltos de uma esfera a outra.

O que chama a atenção de comentadores desta obra de Nietzsche é, em primeira instância, que apesar de suas influências, o filósofo raramente cita estes autores em seus textos publicados, embora o tenha feito em cartas e anotações. Em segunda instância, observa-se que apesar de existir uma base naturalista em seus argumentos, Nietzsche (2008) não se volta inteiramente para eles, permanecendo em seu texto estes argumentos como um plano de fundo, interessante, mas não explícito.

O que se intenta ao desvelar este panorama não é afirmar que Nietzsche aborda a linguagem transformando-a unicamente em uma discussão fisiológica, mas sim que, de fato, Nietzsche, como explicou Moore (2002), se utiliza de termos biológicos e realiza leituras neste sentindo, no entanto, ao escrever ele oferece a estes um acento diferente do que possuíam no original.

\footnotetext{
${ }^{16}$ Tradução livre de "discusses the identification of sensory and motoric regions in the cerebral cortex, as well as experiments showing that electrical stimulation of the latter leads to related muscular moviments. "

${ }^{17}$ Tradução livre de "This translational description of sensory perception is explained in even more detail in Otto Funke's Lehrbuch der Physiologie (1855-57), which Nietzsche read in 1870 shortly after he turned his attention to the problem of language and while he was already working on his later lectures on rhetoric. Presumably Funke's voluminous work influenced Nietzsche's scientific knowledge as well as his concept of Übertragung. In fact, Funke is quite explicit and describes the nerve fiber as a "conductor," that is, a "mechanism" that transfers a particular impulse from one end to another, thereby connecting to other nerve fibers. In this respect, Funke concludes, the process involved in human perception must be understood quite literally as a "transmission from fiber to fiber."
} 
Trata-se antes de não ler mais ingenuamente a teoria da metáfora na linguagem em Nietzsche, não a concebendo apenas em seu conceito clássico de metáfora como tradução ou de troca de um significado por outro, contudo, a priori como transferência e ação, sendo pensada de diferentes perspectivas além da filosófica, como, por exemplo, a artística e científica.

O que representa em última instância a linguagem compreendida a partir deste conceito de metáfora como processo de transferência? Vide o excerto abaixo:

Acreditamos saber algo acerca das próprias coisas, quando falamos de árvores, cores, neve e flores, mas, com isso, nada possuímos senão metáforas das coisas, que não correspondem, em absoluto, às essencialidades originais. Tal como o som sob a forma de figuras de areia, assim se destaca o enigmático " $x$ " da coisa em si, uma vez como estímulo nervoso, em seguida como imagem, e, por fim, como som. De qualquer modo, o surgimento da linguagem não procede, pois, logicamente, sendo que o inteiro material no qual e com o qual o homem da verdade, o pesquisador, o filósofo, mais tarde trabalha e edifica, tem sua origem, se não em alguma nebulosa cucolândia, em todo caso não na essência das coisas. (NIETZSCHE, 2008, p.33-34).

O resultado da linguagem enquanto metafórica é que os conceitos, as palavras não têm origem na coisa em si ou em um processo racional lógico, pelo contrário, antes derivam de um local estranho, impreciso, uma cucolância, para utilizar-se de uma expressão do próprio autor. Isto significa que a linguagem não exprime com exatidão o mundo ou a realidade, mas apenas as transferências heterogêneas que o próprio homem cria.

Expondo de outro modo, a linguagem possui uma característica metafórica porque funciona como criação, uma invenção, a arte que auxilia o homem a entrar em contato com aquilo a que ele não possui acesso direto, ou seja, o mundo. Isto implica que no entendimento do mundo o que se conhece sobre a realidade é

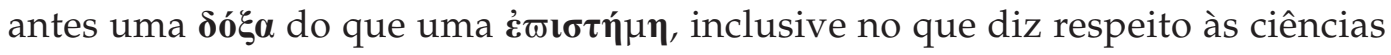
naturais, porém, o homem se esqueceu de sua natureza artística.

Esse movimento de esquecimento para Kofman (1993, p.25) não ocorre em um ponto específico ou por intervenções, é antes um componente natural do processo de criação da linguagem, "É originário, o correlato necessário da atividade metafórica em si, o homem sempre esqueceu que ele é um 'artista desde o início', e que ele permanece um em todas as suas atividades."18

A linguagem não é nada além de uma criação artística desenvolvida pelo próprio homem em sua tarefa de lidar com o mundo, ele cria as palavras e as metáforas, esquecendo-se delas em seguida, ou seja, esquecendo-se da sua própria condição de artista da linguagem e do mundo como ele o enxerga. Neste sentindo, a metáfora é a criação contínua do mundo, a ação de criar a realidade a partir de diferentes esferas adaptando-as ao homem.

O ponto chave para compreender a crítica de Nietzsche de acordo com Bornedal (2010) é atentar para o fato de que a linguagem é tão somente simbólica. No instante em que o homem se esquece deste detalhe e deposita uma crença na linguagem como expressão fiel do mundo, ele se esquece do desempenho artístico e o que faz é um congelar das metáforas como se estas fossem verdades,

\footnotetext{
${ }^{18}$ Tradução livre de "It is originary, the necessary correlate of metaphorical activity itself man has always already forgotten that he is an 'artist from the beginning', and that he remains one in all his activities."
} 
e não processos criativos que sofrem alterações e que possuem um plano de fundo antropológico. ${ }^{19}$

Em uma passagem mais à frente no ensaio, Nietzsche $(2008$, p.39) retoma a ideia de comparação entre o homem, o animal e a relação da linguagem, ao afirmar que o homem é um gênio de criação frente, por exemplo, a abelha, pois: "[...] esta última constrói a partir da cera, que ela recolhe da natureza, ao passo que o primeiro a partir da matéria muito mais delicada dos conceitos, que precisa fabricar a partir de si mesmo."

Vale rememorar que enquanto criação, as metáforas da linguagem também dispõem de características individuais e intuitivas, contrapondo-se aos conceitos que são inflexíveis e se exibem como edifícios gélidos. Esta oposição elaborada por Nietzsche representa para Branco (2011, p.45) “A relação entre metáfora e conceito é uma relação de conflito permanente, e apenas esse conflito entre instinto e intelecto, entre instinto e contra instinto ou movimento e contra-movimento, permite a criação de novas palavras." ${ }^{20}$

Muito poderia ser dito a respeito da linguagem em Nietzsche e sua oposição entre conceito e metáfora, instinto e inconsciente, sobretudo a imagem que o filósofo germânico traz do columbário em seu ensaio, contudo, visando a concentrar os esforços desta breve exposição na questão da metáfora como Übertragung e seu panorama científico, optou-se por não se estender a respeito.

Assim, em suma, atenta-se que em geral o que Nietzsche está disposto a pontuar neste ensaio, utilizando de um tom irônico e artístico por meio da análise da linguagem como metáfora, nada mais é do que, como escreveu Stern (1978, p.67), que "Não há conhecimento de um mundo além do nosso mundo - todas as declarações que fingem tal conhecimento são falsas, enquanto que todas as declarações que afirmam ser verdadeiras contas de nosso mundo são meras tautologias." ${ }^{21}$.

\footnotetext{
${ }^{19}$ Por meio desta chave de leitura da linguagem como processo simbólico Nietzsche realiza uma crítica a noção de verdade, porque a verdade não é tanto uma realidade, mas sim uma linguagem petrificada. Neste sentindo, discorre Bornedal (2010, p.64) “O problema é aqui que a linguagem, que é apenas simbólica (que só pode ser sobre algo), foi transformada em realidade, e a única palavra que representa o assunto é confundido com a coisa em si. Essa linguagem reificada, por exemplo, vê realizada em patologias religiosas e psicóticas; palavras ou sons se tornam fetiches, totens ou mantras e são adorados como tal. Quando as verdades são 'moedas' que perderam seu selo, vale apenas o metal, quando se tornaram sinnlich kraflos, eles são reduzidos a mantras 'patológicos' e vazios. Nietzsche continua a chamar estas palavras de 'metáforas' porque ainda são sinais arbitrários para algo $=\mathrm{x}$, mas em uma definição de retórica clássica, de fato, perderam toda a qualidade metafórica. O pensamento de Nietzsche parece ser que originalmente eles serviram como metáforas, ou seja, como a expressão mais expedita e econômica para um certo estado de coisas, mas desde então eles coagularam, e se esqueceram que eles, uma vez, forneceram um modelo conveniente. Agora, as 'metáforas' de Nietzsche são, em vez disso, uma espécie de antimetáforas mortas." Tradução livre de "The problem is here that language, which is only symbolic (which can only be about something), has been turned into reality, and the word only representing the thing is confused with the thing itself. Such reified language we for example see performed in religious and psychotic pathologies; words or sounds become fetishes, totems, or mantras, and are worshipped as such. When truths are 'coins' having lost their stamp, worth only their metal, when they have become sinnlich kraftlos, they are reduced to such empty 'pathological' mantras. Nietzsche continues to call these words 'metaphors' because they are still arbitrary signs for something $=\mathrm{x}$, but on a classical rhetorical definition they have in fact lost all metaphorical quality. Nietzsche thinking seems to be that originally they served as metaphors, i.e., as the most expedient and economic expression for a certain state-of affairs, but since then they have coagulated, and it is forgotten that they only, once upon a time, provided a convenient model. Now, Nietzsche's 'metaphors' are instead a kind of dead antimetaphors." (BORNEDAL, 2010, p.64).

${ }^{20}$ Tradução livre de "the relation between metaphor and concept is a relation of permanent conflict, and only this conflict between instinct and intellect, between instinct and contra-instinct or movement and contramovement, allows for the creation of new words."

${ }^{21}$ Tradução livre de "There is no knowledge of a world beyond our world - all statements pretending to such knowledge are false, whereas all statements claiming to be true accounts of our world are mere tautology."
} 


\section{Conclusão}

Com o levantamento teórico concluiu-se a importância de retomar os autores que tiveram impacto na formulação nietzschiana do conceito de metáfora. Arthur Schopenhauer contribuiu por meio de suas análises para a formação de Nietzsche da relação entre linguagem, verdade e conhecimento a partir das análises kantianas deste. Gerber influenciou predominantemente entre os anos de 1872 e 1873, sobretudo na temática da retórica e no conceito de linguagem, que tem por base a arte. Já Lichtenberg teve profundo impacto na concepção aforística de Nietzsche, que começa a ser percebida no ensaio aqui abordado, e também devido a sua noção de corpo e linguagem tratados à luz do campo das ciências naturais.

Conclui-se que em Verdade e Mentira no sentido Extra-Moral Nietzsche concebe as palavras como traduções, metáforas, de modo que todo conhecimento tem sua base artística a partir de um movimento cognitivo de diferentes saltos em esferas, ou seja, diferentes níveis de criação até que o sujeito possa usar as palavras e com elas habitar o mundo.

A leitura de Nietzsche, no entanto, não é arbitrária e se aloca em um contexto de produção influenciado por suas leituras de linguística, mas também de fisiologia, medicina e psicologia. Estas leituras refletiram o próprio vocabulário do filósofo ao utilizar o termo Übertragung que faz parte dos mais diversos estudos durante o século XIX, sobretudo no campo das ciências naturais.

Por fim, buscou-se lançar sobre o enxuto ensaio de Nietzsche uma nova chave de interpretação, mais consciente do seu contexto e do plano de fundo do período em que foi escrito, ou seja, reconhecer as leituras de Nietzsche e a situação da ciência em relação ao termo Übertragung no período de 1873.

Correspondência: Laura Elizia Haubert. Pontifícia Universidade Católica de São Paulo - PUC-SP. Faculdade de Filosofia, Comunicação, Letras e Artes. Rua Monte Alegre, 984. Perdizes. São Paulo - SP - Brasil. CEP: 05014-901. E-mail: eliziahaubert@hotmail.com

Conflito de interesses: Nenhum

Todos os autores leram e aprovam a versão final submetida à revista Em curso. 


\section{Bibliografia}

ABEL, Günter. Verdade e interpretação. Trad. Claudemir Luís Araldi. Cadernos Nietzsche. n. 12, São Paulo, 2002. [Grupo de estudos Nietzsche.].

BORNEDAL, Peter. The surface and the abyss: Nietzsche as philosopher of mind and knowledge. Berlin/New York: De Gruyter, 2010. [Monographien und Texte zur Nietzsche-Forschung].

BRANCO, Maria João Mayer. Nietzsche on metaphor, musicality and style. From language to the life of the drives. In: CONSTÂNCIO, João; BRANCO, Maria João Mayer. Nietzsche on instinct and language. Berlim/Boston: De Gruyter, 2011.

BROBJER, Thomas H. Nietzsche's philosophical context: an intellectual biography. University of Illinois Press: Urbana and Chicago, 2008.

BROWN, Kristen. Nietzsche and Embodiment: discerning bodies and non-dualism. Albany: State University of New York Press, 2006.

CLOEREN, Hermann J. Language and thought: german approaches to analytic philosophy in the 18th and 19th centuries. Berlin/New York: de Gruyter, 1988.

CRAWFORD, Claudia. The beginnings of Nietzsche's theory of language. Berlin/New York: de Gruyter, 1988. (Monographien und Texte zur Nietzsche-Forschung).

DE MAN, Paul. Nietzsche's theory of rhetoric. Symposium: a quartel jornal in modern literatures. 28:1, 33-51, 1974.

DENAT, Céline. "To speak in images": the status of Rhetoric and Metaphor in Nietzsche's new language. In: CONSTÂNCIO, João; MAYER BRANCO, Maria João. As the spider spins: essays on Nietzsche's critique and use of language. Berlin/Boston: De Gruyter, 2012.

EMDEN, Christian J. Nietzsche on language, consciousness, and the body. University of Illinois Press: Urbana and Chicago, 2005.

Nietzsche's naturalism: philosophy and the life sciences in the nineteenth century. Cambridge: Cambridge University Press, 2014.

FINK, Eugen. A filosofia de Nietzsche. Tradução de Joaquim Lourenço Duarte Peixoto. Editorial Presença, Lisboa, 1993.

FORSTER, Michael N. German philosophy of language: from Schlegel to Hegel and beyond. Oxford: Oxford University Press, 2013.

GLOCK, Hans-Johann. Philosophy of language. In: FORSTER, Michael N.; GJESDAL, Kristin. The Oxford handbook of German philosophy in the nineteenth-century. Oxford: Oxford University Press, 2015.

GRAY, Jonathan. Hamann, Nietzsche, and Wittgenstein on the language of philosophers. In: ANDERSON, Lisa Marie. Hamann and the tradition. Evanston, Illinois: Northwestern University Press, 2012.

HAAR, Michel. Nietzsche and Metaphysics. Translated and edited by Michael Gendre. Albany: State University of New York Press, 1996.

JANZ, Curt Paul. Friedrich Nietzsche: uma biografia, volume I: infância, juventude, os anos em Basileia. Tradução de Markus A. Hediger. Petrópolis, RJ: Vozes, 2016.

KLEIN, Wayne. Nietzsche and the promise of philosophy. Albany: State University of New York Press, 1997.

KOFMAN, Sarah. Nietzsche and metaphor. Translated, with an introduction additional notes, and a bibliography by Duncan Large. London: The Athlone Press, 1993.

KREMER MARIETTI, Angèle. Nietzsche, metaphor and cognitive science. DOGMA: revue de philosophie et de sciences humaines. França, nº3, 2008.

LACOUE-LABARTHE, Philippe. The subject of philosophy. Translated by Thomas Trezise, Hugh J. Silverman, Gary M. Cole, Timothy D. Bent, Karen McPherson and Claudette Sartiliot. Minneapolis/ London: University of Minnesota Press, 1993. [Theory and History of Literatura, vol. 83].

LLINARES, Joan B. Filosofia e linguagem no jovem Nietzsche. Cadernos Nietzsche. vol. 36, n.1, pp.4581, 2015.

LOPES, Rogério Antonio. Elementos de retórica em Nietzsche. São Paulo: Edições Loyola, 2006.

MATTIOLI, William. Metáfora e ficcionalismo no jovem Niezsche. Revista Trágica: estudos sobre Nietzsche. Vol.3, nº 2, pp. 39-60, 2010. 
MOORE, Gregory. Nietzsche, biology and metaphor. Cambridge: Cambridge University Press, 2002. NERLICH, Brigitte; CLARKE, David D. Mind, Meaning and metaphor: the philosophy and psychology of metaphor in 19th-century Germany. History of The Human Sciences. London, Vol.14, n.2, pp.39-61, 2014.

NIETZSCHE, Friedrich. Sobre a verdade e mentira. Tradução e organização de Fernando de Moraes Barros. São Paulo: Hedra, 2008. (Estudos Libertários).

SÁ MOREIRA, Fernando de. Linguagem e verdade: a relação entre Schopenhauer e Nietzsche em Sobre verdade e mentira no sentindo extramoral. Cadernos Nietzsche, São Paulo, nº 33, p. 273-300, 2013.

SANTIAGO GUERVÓS, Luis Enrique de. Introducción: el poder de la palabra: Nietzsche y la retórica. In: NIETZSCHE, Friedrich. Escritos Sobre Retórica. Edición y traducción de Luis Enrique de Santiago Guervós. Madrid: Editorial Trotta, 2000.

STERN, J.P. Nietzsche and the Idea of Metaphor. In: PASLEY, Malcolm. Nietzsche: imagery and thought, a collection of essays. Berkeley and Los Angeles: University of California Press, 1978.

WESTERDALE, Joel. Nietzsche's aphoristic challenge. Berlin/New York: de Gruyter, 2013.

Recebido em: 17/Mar/2017 - Aceito em: 18/Set/2017. 